\title{
The oligomeric state of thyroid receptor regulates hormone binding kinetics
}

\author{
Suzana T Cunha Lima ${ }^{1,2}$ and Edson D Rodrigues ${ }^{1,3}$ \\ ${ }^{1}$ Diabetes Center, University of California, 513 Parnassus Avenue, 94143 San Francisco, California, USA \\ ${ }^{2}$ Instituto de Biologia, Universidade Federal da Bahia, Rua Barão de Geremoabo 147, Campus de Ondina, 40170-290 Salvador, Bahia, Brazil \\ ${ }^{3}$ Centro Universitário da Bahia - FIB, Rua Xingu, 179, 41770 Salvador, Bahia, Brazil \\ (Correspondence should be addressed to S T Cunha Lima at Instituto de Biologia, Universidade Federal da Bahia; Email: stcunhalima@ufba.br)
}

\begin{abstract}
We previously reported that mutations in the thyroid hormone receptor (TR) surface that mediates dimer and heterodimer formation do not alter affinity for cognate hormone (triiodothyronine $\left(T_{3}\right)$ ) yet dramatically enhance $\mathrm{T}_{3}$ association and dissociation rates. This study aimed to show that TR oligomeric state influences binding and dissociation kinetics. We performed binding assays using marked hormone $\left({ }^{125} \mathrm{I}_{-} \mathrm{T}_{3}\right)$ and TRs expressed and purified by different methods. We find that $\mathrm{T}_{3}$ associates with TRs with biphasic kinetics in solution; a rapid step (half-life $\pm 0 \cdot 1 \mathrm{~h}$ ) followed by a slower second step (half-life $\pm 5 \mathrm{~h}$ ) and that purification of monomers suggests that biphasic kinetics are due to the presence of monomers and dimers in
\end{abstract}

our preparations. In support of this idea, incubation of TR ligand binding domain monomers with corepressor peptide induces dimer formation and decreases association rates and $\mathrm{T}_{3}$ binds to, and dissociates from, a TR $\beta$ mutant that only forms dimers (TR $\beta$ D 355R) with slow single-phase kinetics. In addition, heterodimer formation with retinoid $\mathrm{X}$ receptors also influences ligand binding kinetics. Together, these results suggest that the dimer/heterodimer surface is allosterically coupled to the hormone binding pocket and that different interactions at this surface exert different effects on ligand binding that may be relevant for TR actions in the cell.

Journal of Endocrinology (2011) 210, 125-134

\section{Introduction}

The nuclear receptor (NR) family of transcription factors includes receptors for thyroid hormone $(\mathrm{TH})$, steroids, vitamins $\mathrm{A}$ and $\mathrm{D}$, and other small hydrophobic molecules (Laudet \& Gronemeyer 2002). NRs play widespread roles in growth, development, and homeostasis, and NR signaling frequently becomes deregulated in disease. Consequently, $\mathrm{TH}$ receptors (TRs) are important targets for pharmaceutical development (Baxter \& Webb 2009). Agonists selective for the TR $\beta$ versus the TR $\alpha$ isoform reduce circulating levels of cholesterol, lipoprotein, and triglycerides and promote loss of adipose tissue in animal models, without eliciting harmful effects on heart, bone, and muscle. Thus, TR $\beta$-selective analogs might reduce heart disease and prevent obesity in humans. TR antagonists could be rapid acting treatments for hyperthyroidism and cardiac arrhythmias (Webb et al. 2002). Improved understanding of the fundamental mechanisms of TR ligand binding, and how ligand binding is coupled to alterations in TR function, will facilitate development of improved versions of these compounds that interact stably and selectively with TRs and other new drugs.

The nature of the TR binding site for cognate hormone $\left(3,3^{\prime}, 5\right.$-triiodo-L-thyronine, triiodothyronine $\left.\left(\mathrm{T}_{3}\right)\right)$ is well understood (Moore et al. 2010). TRs, like most NRs, are single polypeptide chains comprising three domains. $\mathrm{T}_{3}$ binding is mediated by the $\mathrm{C}$-terminal ligand binding domain (LBD) that contains coregulator binding sites and the major surface that mediates homodimer and heterodimer formation with the retinoid X receptor (RXR) and is linked to the other domains: the central DNA binding domain (DBD) and an $\mathrm{N}$-terminal activation domain. X-ray structures of $\operatorname{TR} \alpha$ and TR $\beta$ LBDs in complex with $T_{3}$ (Webb et al. 2002), and structures of other NR LBDs obtained by other groups (Bleicher et al. 2008, Sonoda et al. 2008), reveal that agonists are buried in the core of the domain.

The major mechanism known to couple NR hormone binding to changes in gene expression is also well understood: ligand induces packing of the receptor LBD C-terminal helix against the body of the receptor, occluding part of a binding surface for corepressors and completing a coactivator binding site, with exchange of coregulators at hormone-regulated promoters (Glass \& Rosenfeld 2000). Analysis of effects of TR mutants on gene expression and coregulator binding and a crystal of the TR LBD in complex with a short coactivator peptide confirms that this formulation applies to TRs (Darimont et al. 1998, Feng et al. 1998). 
In contrast, factors that influence the stability of bound $\mathrm{T}_{3}$, and mechanisms involved in $\mathrm{T}_{3}$ entry and exit from the pocket, are incompletely characterized. $\mathrm{H} 12$ plays a major role in stabilizing bound ligand in TRs and other NRs (Carlson et al. 1997, Huber et al. 2003b, Sandler et al. 2004, Nettles \& Greene 2005), possibly by serving as a gate for a ligand entry/exit route or by stabilizing the ligand/receptor complex. Nevertheless, other regions of the TR $\beta$ LBD surface are important for stable ligand binding. TR $\beta$ mutations that arise in the human resistance to TH syndrome increase $T_{3}$ dissociation rates by destabilizing the loop between $\mathrm{H} 1$ and $\mathrm{H} 3$, on the opposite side of the LBD from H12 (Huber et al. 2003a,b) or by disrupting surface exposed clusters of charged amino acids on $\mathrm{H} 7 / \mathrm{H} 8$ and $\mathrm{H} 11$, below the TR dimer/heterodimer surface at the junction of H10 and H11 (Togashi et al. 2005b). Finally, molecular dynamic simulations suggest that $T_{3}$ may dissociate from TRs in three ways: under $\mathrm{H} 12$ or through cavities that form between $\mathrm{H} 1$ and $\mathrm{H} 3$ or H8 and H11 (Martinez et al. 2005, 2006). Thus, different regions of the TR $\beta$ LBD surface are required for stable $\mathrm{T}_{3}$ binding and several regions of the TR surface could rearrange in response to hormone binding.

TRs exist in many different oligomeric forms and $T_{3}$ regulates the distribution of these species (Yen 2001). TRs generally exist as heterodimers with the closely related RXR in living cells but also form monomers, dimers, trimers, and tetramers in solution in the absence of RXR. A lowresolution structure of TR dimers and tetramers (Figueira et al. 2007) showed that the holo TR $\beta$ DBD-LBD construct forms a homodimer with LBD-DBD pairs in close contact, and the apo hTR $\beta D B D-L B D$ construct forms tetramers that resemble bulged cylinders with pairs of LBD dimers in a head-to-head arrangement. RXR-TRs, TR monomers, and TR homodimers activate transcription from different $\mathrm{TH}$ response elements (TREs) in yeast and mammalian cells, indicating that each species is functionally important (Velasco et al. 2007). Nevertheless, even though RXR-TR and TR-TR homodimer formation involves a common hydrophobic surface at the junction of H10 and H11 (Ribeiro et al. 2001), fairly distant from the ligand binding pocket (LBP), $\mathrm{T}_{3}$ selectively inhibits $\mathrm{TR}$ homodimer formation on DNA (Yen 2001, Togashi et al. 2005b). Thus, basic thermodynamic principles predict that oligomerization should selectively affect $T_{3}$ interactions with receptor. Recent hydrogen/deuterium (H/D) exchange experiments (Figueira et al. 2011) revealed hormone-dependent changes in the dimer surface at $\mathrm{H} 10-\mathrm{H} 11$, confirming allosteric coupling between the LBP and the dimer surface. Furthermore, we previously showed that $T_{3}$ binds TR $\beta$ mutants that only form monomers (TR $\beta$ P419R, L422R, and M423R) with similar affinity, yet associates with and dissociates from these mutants much more rapidly than wild-type TRs (Cunha Lima et al. 2009). In this study, we show that TR dimer/heterodimer interactions influence ligand association/dissociation kinetics and we propose that homodimer formation induces allosteric conformational changes in the TR-LBD that impair $\mathrm{T}_{3}$ association and dissociation, whereas RXR-TR heterodimer formation allows rapid exchange of bound $T_{3}$. These influences may be relevant for differential function of TR oligomers in the cell.

\section{Materials and Methods}

\section{Plasmids}

Expression vectors for full-length TR $\alpha$ and $\operatorname{TR} \beta$ (pCMXTR $\beta$ and $\mathrm{pCMX}-\mathrm{TR} \alpha$ ) and TR $\beta$ mutants (TR $\beta \mathrm{P} 419 \mathrm{R}$, L422R, M423R, and D355R) were previously described (Ribeiro et al. 2001). TR $\beta$-LBD and DBD-LBD (amino acids 202-461 and 102-461) were expressed as fusion proteins containing an $\mathrm{N}$-terminal poly-histidine tag. The TR $\beta$ LBD expression vector was previously described (Wagner et al. 2001). The DBD-LBD expression vector was created by PCR amplification using appropriate primers containing NdeI/BamHI restriction sites and cloning into pET28 (EMD Chemicals/Novagen, Gibbstown, NJ, USA). Expression vectors for TR $\beta$ LBD L422R and D355R mutants were created using the QuickChange XL Site-Directed Mutagenesis Kit (Agilent Technologies/Stratagene, Santa Clara, CA, USA). Mutation of target sequences was verified by automated DNA sequence (Elim Biopharmaceuticals, Inc., Hayward, CA, USA).

\section{Protein expression}

Unless stated, TRs and TR truncations were expressed in TNT T7 Quick in vitro coupled transcription/translation kits, according to manufacturer's protocols (Promega). For some experiments, TR $\beta$ LBDs and TR $\beta$ LBD mutants were expressed in Escherichia coli (E. coli) BL21-DE3 strain (Huber et al. 2003a,b). Cultures (1 l ) were grown overnight (12-18 h) at room temperature $\left(20-23^{\circ} \mathrm{C}\right)$ in $2 \mathrm{X} \mathrm{L}$-broth + antibiotic to $\mathrm{OD}_{600}=1 \cdot 0$. Protein production was initiated with isopropylthiogalactoside (Sigma, final concentration $1 \mathrm{mM}$ ) and cultures were incubated for a further $4-6 \mathrm{~h}$ at room temperature. Bacteria were pelleted by centrifugation at $2800 \mathrm{~g}$. for $10 \mathrm{~min}$. The pellet was drained and frozen at $-80^{\circ} \mathrm{C}$.

\section{Purification of TR $\beta$ LBDs from bacterial extracts}

Frozen pellets of 11 bacterial cultures were thawed slowly on ice and resuspended in $20 \mathrm{ml}$ TST buffer $(50 \mathrm{mM}$ Tris with $150 \mathrm{mM} \mathrm{NaCl}, 0 \cdot 1 \%$ monothioglycerol, and $1 \mathrm{mM}$ phenylmethylsulphonyl fluoride (PMSF), $\mathrm{pH} 8 \cdot 0$; Glass \& Rosenfeld 2000). Lysozyme was added to $10 \mu \mathrm{g} / \mathrm{ml}$ and the mix was shaken at $4{ }^{\circ} \mathrm{C}$ for $30 \mathrm{~min}$. This suspension was sonicated for $60 \mathrm{~s}$ and centrifuged at $18000 \mathrm{~g}$ for $30 \mathrm{~min}$ (Sorvall RC 5B Plus with SS-34 rotor, GMI Inc., Ramsey, Minnesota, USA). Supernatant containing histidine-tagged TR LBDs was mixed with $60 \mu \mathrm{l}$ equilibrated Talon Metal Affinity Resin prepared according to manufacturer's 
instructions (BD Biosciences, San Diego, CA, USA) and shaken for $1 \mathrm{~h}$ at $4{ }^{\circ} \mathrm{C}$. Talon resin was pelleted and washed twice in ice-cold $50 \mathrm{mM} \mathrm{NaPO}_{4} \mathrm{pH} 7 \cdot 5,300 \mathrm{mM} \mathrm{NaCl}$, $0 \cdot 1 \%$ MTG, $1 \mathrm{mM}$ PMSF, and $2 \mathrm{mM}$ ATP. Histidine-tagged TR $\beta$ LBDs were eluted at $4{ }^{\circ} \mathrm{C}$ in the same buffer $(2 \mathrm{ml})$ $+200 \mathrm{mM}$ imidazole. TR protein concentration in flow through was determined by standard colorimetric assay using Coomassie Plus protein reagent (Pierce, Rockford, IL, USA) versus a BSA curve and the integrity of protein was verified by analysis on $10 \%$ SDS-polyacrylamide gels. This method generally yielded 7-20 mg of pure (>95\%) TR LBD per liter of culture.

Where stated, TR $\beta$ LBDs were further purified by gel filtration and $4 \mathrm{ml}$ of TR $\beta$ LBD solution $(2 \mathrm{mg} / \mathrm{ml})$ was concentrated in Amicon Ultra-4 filter $(10 \mathrm{kDa}$ cut) and applied to a Superdex 200-HR Gel-Filtration column (Pfizer/Pharmacia, New York, NY, USA) and eluted in $10 \mathrm{mM}$ HEPES and $1 \mathrm{mM}$ dithiothreitol. Fractions $(250 \mu \mathrm{l})$ were collected on ice. TR was detected by measuring absorbance at $280 \mathrm{~nm}$ and integrity was verified by SDSPAGE analysis of each fraction.

\section{Hormone binding and kinetics}

$\mathrm{T}_{3}$ binding affinities $\left(K_{\mathrm{d}}\right)$, association $\left(K_{\mathrm{on}}\right)$, and dissociation $\left(K_{\text {off }}\right)$ were determined according to previous work (Suthers et al. 1976) with small modifications (Cunha Lima et al. 2009). Approximate amounts of expressed TRs were determined by measuring the amount of total $T_{3}$ binding activity in singlepoint binding assays: different dilutions of protein preparation were incubated overnight at $4{ }^{\circ} \mathrm{C}$ with $1 \mathrm{nM} \mathrm{L-3,5}$, $\left.3^{\prime}-{ }^{125} \mathrm{I}\right] \mathrm{T}_{3}$ (Perkin Elmer/NEN Life Science, Waltham, MA, USA) in a $100 \mu$ l binding buffer $(400 \mathrm{mM} \mathrm{NaCl}, 20 \mathrm{mM}$ $\mathrm{KPO}_{4}, \mathrm{pH} 8,0.5 \mathrm{mM}$ EDTA, $1.0 \mathrm{mM} \mathrm{MgCl}_{2}$, and $10 \%$ glycerol) containing $1 \mathrm{mM}$ monothioglycerol and $50 \mu \mathrm{g}$ calf thymus histones (EMD Biosciences/Calbiochem, Gibbstown, NJ, USA). Bound ${ }^{125} \mathrm{I}_{-} \mathrm{T}_{3}$ was isolated by gravity flow through a $2 \mathrm{ml}$ course Sephadex G-25 column (Pfizer/ Pharmacia) to separate bound from free ligand and bound ligand was quantified using a $\gamma$-counter (COBRA/Packard Instruments, Meriden, CT, USA). The approximate number of binding sites per unit volume in the starting mix was calculated from specific activity of radiolabeled $T_{3}$ (3824 c.p.m. $=1 \mathrm{fmol}$ ).

For saturation binding analyses, about $20 \mathrm{fmol}$ of TR protein was incubated overnight at $4{ }^{\circ} \mathrm{C}$ with varying concentrations of ${ }^{125} \mathrm{I}_{-} \mathrm{T}_{3}$. The amount of ${ }^{125} \mathrm{I}-\mathrm{T}_{3}$ was verified by precount in each aliquot of buffer, prior to addition of protein. Next morning, the amount of bound versus free ${ }^{125} \mathrm{I}_{-} \mathrm{T}_{3}$ was determined by passage over the Sephadex G-25 column, as above. $K_{\mathrm{d}}$ values were calculated by fitting saturation curves to the equations of Swillens using the GraphPad Prism program (GraphPad Software V3.03, San Diego, CA, USA). In these conditions, non-specific binding of ${ }^{125} \mathrm{I}_{-} \mathrm{T}_{3}$ to unprogrammed reticulate lysates was negligible, $<1 \%$ of that observed in the presence of $20 \mathrm{fmol}$
TRs, as was residual binding of $1 \mathrm{nM}{ }^{125} \mathrm{I}_{-} \mathrm{T}_{3}$ obtained in the presence of a 1000-fold excess of unlabeled $\mathrm{T}_{3}$ (not shown). Labeled $\mathrm{T}_{3}$ applied to the column in the absence of TRs only dissociates after several hours of repeated washing and does not contribute to measurements of bound $T_{3}$ (not shown). Thus, most (>99\%) of the labeled ligands that pass through the Sephadex G-25 column correspond to TR bound to $\mathrm{T}_{3}$.

\section{$T_{3}$ association and dissociation rates}

$\mathrm{T}_{3}$ association $\left(K_{\mathrm{on}}\right)$ and dissociation $\left(K_{\mathrm{off}}\right)$ rates were determined using similar methods to that described for saturation binding assays, with the following modifications.

For $K_{\text {on }}$, unliganded TR preparations were added to binding buffer containing $1.5 \mathrm{nM}{ }^{125} \mathrm{I}_{-} \mathrm{T}_{3}$ to a final concentration of 20 fmols TRs per $100 \mu$ of buffer. Aliquots $(100 \mu \mathrm{l})$ were then applied at various times to Sephadex G25 columns to separate bound from unbound $\mathrm{T}_{3}$. Binding curves and $K_{\text {on }}$ values were calculated by non-linear regression analysis using one- and two-phase association growth models with GraphPad Prism Software. The one-phase exponential association equation used was $Y=Y_{\max }\left(1-\mathrm{e}^{-K X}\right)$, where $X$ denotes time and $Y$ specific binding. The variable $k$ in the exponential association equation is the observed rate constant, $k_{\mathrm{ob}}$, expressed in units of inverse time. The twophase exponential association equation used was $Y=Y_{\max 1}\left(1-\mathrm{e}^{-K_{1} X}\right)+Y_{\max 2}\left(1-\mathrm{e}^{-K_{2} X}\right), k_{1}$ being the first observed rate constant, $k_{\mathrm{ob} 1}$, and $k_{2}$ the second observed rate constant, $k_{\mathrm{ob} 2}$, according to Motulsky \& Christopoulos (2003). The program identifies the best fit (one/two phase) for each curve.

For $K_{\text {off }}$, TRs were incubated overnight with saturating $(1 \mathrm{nM}){ }^{125} \mathrm{I}_{-} \mathrm{T}_{3}$ at $4{ }^{\circ} \mathrm{C}$ (Suthers et al. 1976, Glass \& Rosenfeld 2000). Unlabeled $T_{3}$ was added to a final concentration of $1 \mu \mathrm{M}$ (1000-fold excess) the following morning and aliquots were taken at various times and applied to Sephadex G-25 columns to determine how rapidly labeled ligand dissociates from TR. Binding curves and $\mathrm{k}_{\text {off }}$ values were calculated using the GraphPad Prism one-phase exponential decay model.

\section{Non-denaturing PAGE}

TRs $(1 \mu \mathrm{g})$ diluted in $10 \mathrm{mM}$ HEPES to a final volume of $10 \mu \mathrm{l}$ were mixed with $10 \mu \mathrm{l}$ loading buffer (final concentration $125 \mathrm{mM}$ Tris, $20 \%$ glycerol, and $1 \mu \mathrm{g}$ bromophenol blue) and applied to a pre-cast $4-15 \%$ Tris- $\mathrm{HCl}$ gel (Bio$\mathrm{Rad})$. Proteins were separated in Tris-glycine running buffer SDS in the cold room for $1 \mathrm{~h}$ at $150 \mathrm{~V}$ and $4{ }^{\circ} \mathrm{C}$ versus $1 \mu \mathrm{g}$ BSA as a sizing and loading control. Where specifically mentioned, TRs were preincubated $\pm 10 \mathrm{nM} \mathrm{T}$ or $100 \mu \mathrm{M}$ hybrid N-CoR interaction domain (ID) peptide (Marimuthu et al. 2002), sequence N-RGKTTITAANFIEDIIRKALMGSFDD-C, or vehicle for $10 \mathrm{~min}$. 


\section{Analytical ultracentrifugation}

TR LBD $(0.2 \mathrm{mg}$; purified from bacterial extracts by incubation with talon resin and eluted as described above) was subjected to analytical ultracentrifugation in the presence or absence of $25 \mu \mathrm{M} \mathrm{T}_{3}$ in an Optima XLA (Beckman Coulter, Brea, CA, USA) equipped with spectrophotometric and interferometer optics. Samples were loaded into two-channel velocity sedimentation cells and placed into an An60Ti rotor to spin at $300000 \mathrm{~g}$ at $4{ }^{\circ} \mathrm{C}$. In total, 30 absorbance scans were collected at $280 \mathrm{~nm}$ in $10 \mathrm{~min}$ intervals. The data was analyzed with SedFit $8.9 \mathrm{~g}$ Software (NIH) to model the $\mathrm{c}(\mathrm{s})$ continuous distribution of Lamm equation solutions.

\section{Gel shifts}

Binding of TRs and RXR-TRs to DNA were assayed as described previously (Cunha Lima et al. 2009).

\section{Results}

\section{$T_{3}$ binds TRs with biphasic kinetics}

We first examined association of $\mathrm{T}_{3}$ with in vitro translated full-length TR $\beta$ at $4^{\circ}\left(K_{\text {on }}\right.$; Fig. 1A). Unexpectedly, we found that the association curve exhibited better fit with the biphasic kinetics than with typical monophasic kinetics. The same experiment was performed together with TR $\alpha$ (Fig. 1B). $T_{3}$ bound rapidly to about $50 \%$ of TRs $\left(K_{\text {on }} \mathrm{T}_{1 / 2}=0 \cdot 1 \mathrm{~h}\right.$, ranging from 0.06 to $0.15 \mathrm{~h}$ in different experiments) and more slowly to the remaining TRs $\left(K_{\text {on }} \mathrm{T}_{1 / 2}=4.7 \mathrm{~h}\right.$, ranging from $3 \cdot 85$ to $7 \cdot 4 \mathrm{~h}$ ). Equilibrium was generally only achieved after more than $8 \mathrm{~h}$ of incubation of $\mathrm{T}_{3}$ with TR.

Biphasic $\mathrm{T}_{3}$ association kinetics was also seen with versions of TR $\beta$ that contained only the DBD and LBD (Fig. 1C) or LBD (Fig. 1D) and with purified preparations of TRs expressed in different systems, including full-length TR $\beta$ expressed in $\mathrm{Sf} 9$ insect cells and preparations of TR DBDLBD and LBDs expressed in E. coli (not shown, and see below). This suggests that biphasic kinetics is not caused by contaminating activities contained within a particular expression system.

Others (and ourselves) have previously examined equilibrium binding of THs to, and dissociation from, TRs and various TR truncations and found no evidence for multiple $\mathrm{T}_{3}$ binding sites (Suthers et al. 1976, Nguyen et al. 2002, 2005, Cunha Lima et al. 2009). The data in Fig. $1 \mathrm{E}$ confirm that $\mathrm{T}_{3}$ binds in vitro translated full-length TR $\beta$ with apparent equilibrium $\left(K_{\mathrm{d}}\right)$ of $108 \mathrm{pmol}$ and the $\mathrm{T}_{3}-\mathrm{TR}$ saturation curve is characterized by a single component (one-phase exponential growth). Furthermore, $\mathrm{T}_{3}$ dissociated from in vitro translated full-length $\operatorname{TR} \beta$ at $4^{\circ}$ with monophasic kinetics (one-phase exponential decay; Fig. 1F; $K_{\text {off) }}$. Thus, $\mathrm{T}_{3}$ associates with TRs with biphasic kinetics yet dissociates with monophasic kinetics.

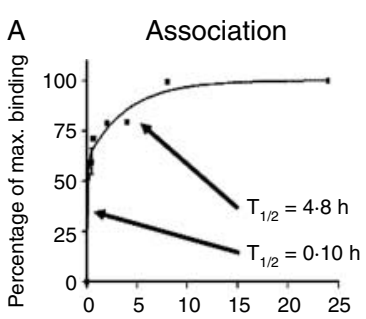

B

TR full length

C TR $\beta$ DBD LBD

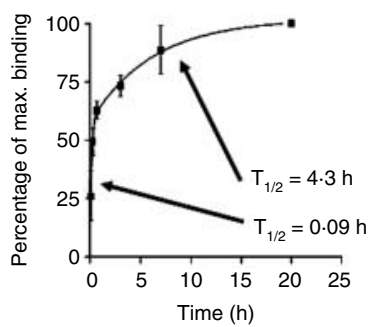

D

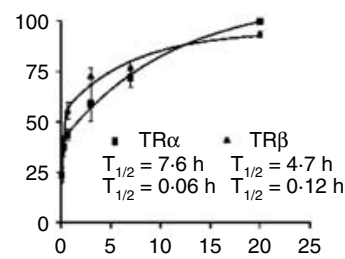

TR $\beta$ LBD

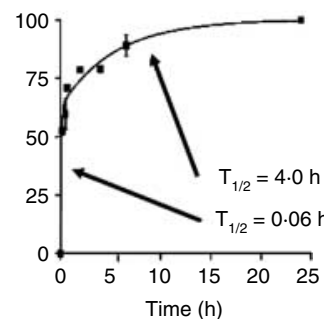

$\mathrm{F}$

Dissociation
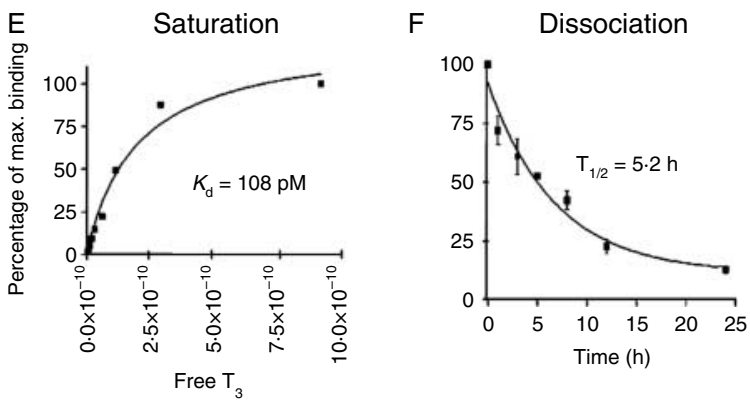

Figure $1 \mathrm{~T}_{3}$ binds TR with biphasic kinetics but exhibits monophasic saturation binding and dissociation curves. (A) Association kinetics of radiolabeled $\mathrm{T}_{3}$ with 20 fmols of full-length TR $\beta$, in vitro translated material. Rapid and slow phases of association are marked with arrows and calculated half-lives $\left(\mathrm{T}_{1 / 2}\right)$ of each phase are indicated. (B-D) As for Fig. 1A except that $T_{3}$ association was determined with (B) full-length TR $\alpha,(C)$, TR $\beta$ DBDLBD and (D) TR $\beta$ LBD. (E) Saturation $T_{3}$ binding assays performed with in vitro translated full-length TR $\beta$. $(F)$ Dissociation of $T_{3}$ from TR $\beta$. Radiolabeled $\mathrm{T}_{3}$ was equilibrated with in vitro translated fulllength TR $\beta$ overnight and TR- $T_{3}$ complex is challenged with unlabeled $\mathrm{T}_{3}$. Note single-phase kinetics of the dissociation curve.

TRs form monomers and dimers in solution and $T_{3}$ promotes dimer to monomer conversion

The simplest explanation for results described above is that unliganded TRs comprised two populations with different $\mathrm{T}_{3}$ binding properties and that $\mathrm{T}_{3}$ converts TRs to a single species with uniform ligand binding and dissociation properties (see Discussion). To investigate this hypothesis, we examined the composition of our TR preparations $\pm T_{3}$.

Our data indicate that unliganded TRs form a mix of dimers and monomers in solution and $\mathrm{T}_{3}$ promotes dimer to monomer conversion. Analysis of migration of purified TR $\beta$-LBD preparations on non-denaturing gels revealed two species, which were the approximate size of dimers and monomers, based on comparison with similar proteins of 
A

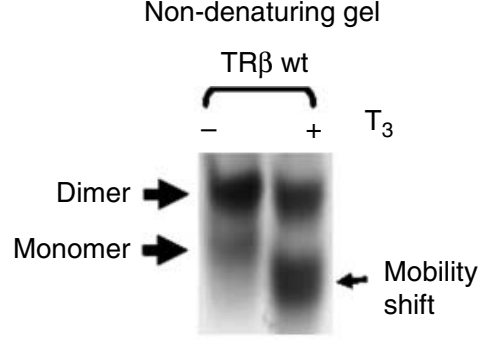

B Analytical ultracentrifugation
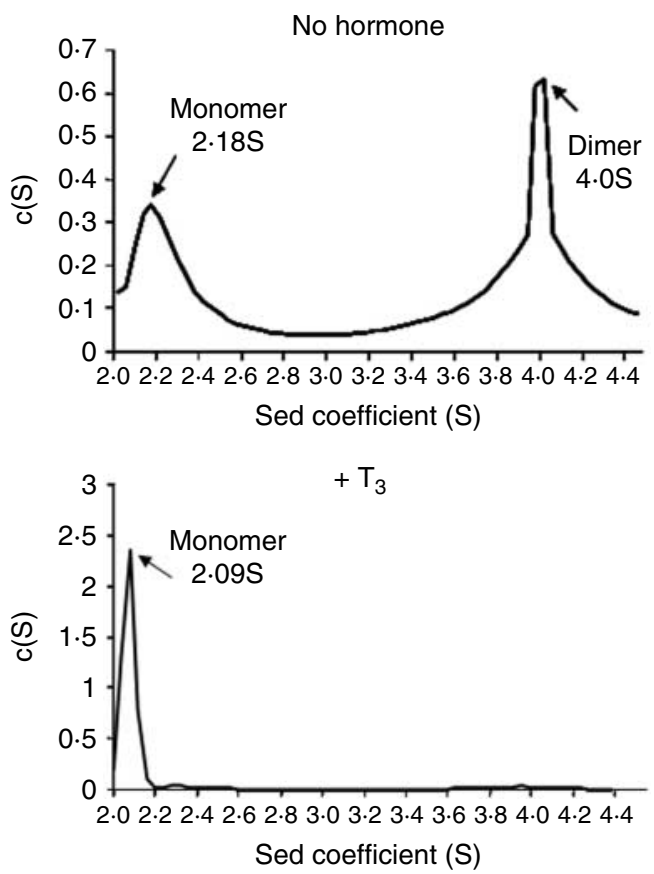

Figure 2 TR LBDs comprised dimers and monomers and $T_{3}$ promotes conversion of dimers to monomers. (A) Unliganded TR LBDs comprised two species and short $T_{3}$ incubations enhance the mobility of the faster migrating species. An image of a nondenaturing polyacrylamide gel used to analyze purified TR $\beta$ LBDs \pm short $(10 \mathrm{~min}) \mathrm{T}_{3}$ treatment. Proteins are visualized by Coomassie blue staining. (B) Sedimentation coefficients of unliganded and liganded LBDs. The panel shows results of an analytical ultracentrifugation experiment. Unliganded TRs form two species ( $50 \mathrm{kDa}$ and $25 \mathrm{kDa}$ ), dimers, and monomers, whereas liganded TRs exist as one species $(24 \mathrm{kDa})$, monomers.

defined molecular weight and pI (Fig. 2A, not shown). Incubation with saturating concentrations of $\mathrm{T}_{3}$ at room temperature for short times $(10 \mathrm{~min})$ increased the proportion of the rapidly migrating species and also specifically increased its mobility.

Analytical ultracentrifugation experiments confirm that unliganded TR-LBDs comprised two forms (Fig. 2B). Furthermore, analysis of sedimentation coefficients of these species $(4 \cdot 0 \mathrm{~S}$ and $2 \cdot 18 \mathrm{~S})$ confirms that they exhibit expected molecular weights of dimers and monomers (MW: $50 \mathrm{kDa}$, $25 \mathrm{kDa}$; Fig. 2B). Addition of $25 \mu \mathrm{M} \mathrm{T} \mathrm{T}_{3}$ before the experiment $(5 \mathrm{~h})$ converted the dimer/monomer mix to a single monomeric species $(2 \cdot 09 \mathrm{~S}, 24 \mathrm{kDa})$. Thus, incubation of the TR dimer/monomer mix with saturating concentrations of $\mathrm{T}_{3}$ yields a preparation that consists of monomers.

\section{TR monomers exhibit rapid $T_{3}$ association rates}

To investigate whether biphasic $T_{3}$ association kinetics is related to existence of dimers and monomers in our TR preparations, we determined rates of $T_{3}$ association with purified TR $\beta$ LBD monomers. $T_{3}$ bound rapidly to TR $\beta$ LBD monomers with single-phase kinetics. Passage of the TR $\beta$-LBD monomer/dimer mix over a sizing column (Superdex 200HR gel filtration) yields monomers, as judged both by elution time relative to molecular weight standards (Fig. 3A) and migration on non-denaturing gels relative to wild-type TRs (Fig. $3 \mathrm{~A}$ inset). Although $\mathrm{T}_{3}$ bound the input TR $\beta$ dimer/monomer mix with characteristic biphasic kinetics $\left(K_{\text {on }} T_{1 / 2}=0.18\right.$ and $\left.6.19 \mathrm{~h}\right)$, it associated with the purified TR $\beta$ monomer preparation with single-phase rapid kinetics $\left(K_{\mathrm{on}} \mathrm{T}_{1 / 2}=0.06\right.$ h; Fig. 3B $)$.

We have previously shown (Cunha Lima et al. 2009) that $\mathrm{T}_{3}$ associates with three TR $\beta$ mutants that impair dimer/ heterodimer formation with rapid kinetics (TR $\beta$ L 422R, M423R, and P419R), reinvestigation of these association curves reveals single-phase kinetics, and that the actual rate of $\mathrm{T}_{3}$ association with these TR mutants was similar to, or even faster than, the first phase of $T_{3}$ association with wildtype TRs $\left(K_{\text {on }} \mathrm{T}_{1 / 2}=0 \cdot 02-0 \cdot 14 \mathrm{~h}\right)$.

\section{$T_{3}$ associates slowly with a TR mutant with enhanced dimerization}

Next, we explored whether $T_{3}$ associates slowly with TR dimers. We have been unable to obtain purified wild-type TR dimers devoid of monomers, so we examined $\mathrm{T}_{3}$ association with a TR mutant (TR $\beta D 355 R)$ that exhibits
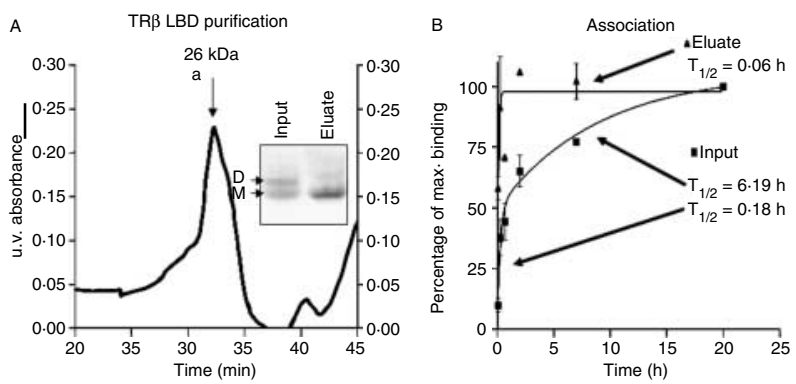

Figure 3 Purified TR $\beta$ LBD monomers bind $T_{3}$ rapidly. (A) Elution curve obtained after a TR $\beta$ LBD dimer/monomer mix is purified over a Superdex gel filtration on HPLC, yielding monomers. Inset shows an image of a non-denaturing polyacrylamide gel, after staining with Coomassie blue, confirming that purified input TR $\beta$ consists of dimers and monomers and that the eluate consists of TR monomers. (B) Determination of $T_{3}$ association kinetics with TRRLBD monomer/dimer mix (input) and purified TR $\beta$ monomers (eluate), experiment performed as in Fig. $1 \mathrm{~A}$. 


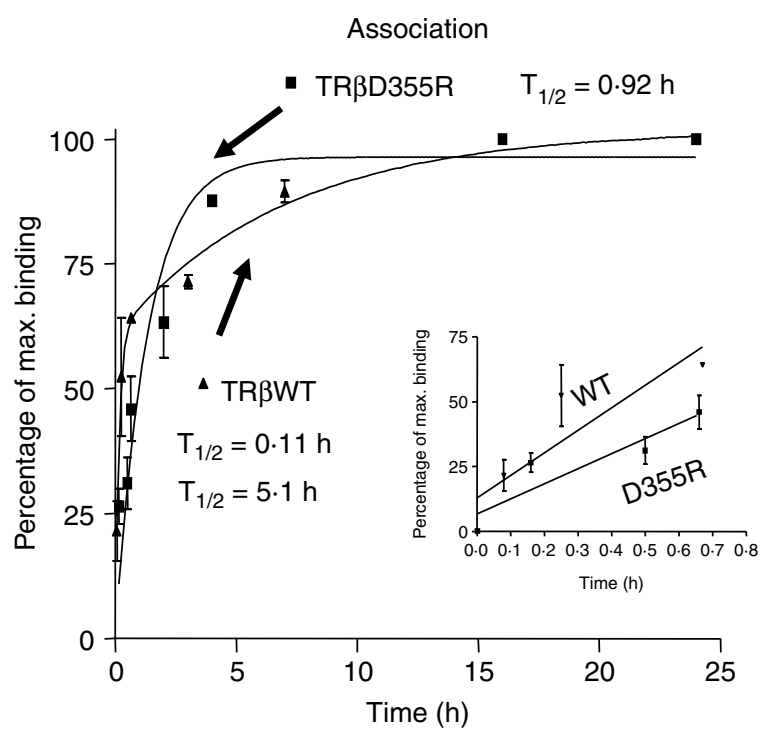

Figure 4 TR $\beta D 355 R$ mutation that enhances dimer formation reduces $T_{3}$ association rates. Determination of $T_{3}$ association with wild-type purified TR $\beta$ LBD and TR $\beta$ LBD D355R, as in Fig. 1A. $\mathrm{T}_{3}$ associates slowly with the TR $\beta$ D355R mutant, but with singlephase kinetics. Inset shows early time points on larger scale.

enhanced dimer formation on DNA in the presence of $\mathrm{T}_{3}$ (Togashi et al. 2005b) and uses an unusual dimer interface that comprises the loop between $\mathrm{H} 10$ and $\mathrm{H} 11$, near the typical dimer interface at the $\mathrm{H} 10-\mathrm{H} 11$ junction, with auxiliary mutant-specific contacts between $\mathrm{H} 8$ and $\mathrm{H} 6$ (Jouravel et al. 2009).

TR $\beta D 355 R$ exhibits enhanced dimer formation on DNA and in solution, as judged by non-denaturing gel electrophoresis and sizing columns (Togashi et al. 2005b, Jouravel et al. 2009 and not shown). Analysis of association rates revealed that TR $\beta D 355 R$ bound $T_{3}$ with single-phase kinetics characterized by slow on rate $\left(K_{\mathrm{on}} \mathrm{T}_{1 / 2}=0.92\right.$ vs $0.06 \mathrm{~h}$ for purified LBD monomers, Fig. 4 and Table 1). This represents further evidence that biphasic association kinetics is only seen in the presence of TR dimers and monomers and further suggests that the slower component of these biphasic on rates reflects $T_{3}$ association with dimers.
Corepressor induces TR LBD dimer formation and biphasic $T_{3}$ association kinetics

Next, we examined effects of a short $\mathrm{N}-\mathrm{CoR}$ peptide corresponding to an NR ID that is known to stabilize the unliganded TR $\beta$ LBD (Pissios et al. 2000, Webb et al. 2000), on TR monomer/dimer equilibrium and $\mathrm{T}_{3}$ association kinetics. Figure $5 \mathrm{~A}$ shows that incubation of purified unliganded TR $\beta$ LBD monomers with the $\mathrm{N}-\mathrm{CoR}$ peptide increased the amount of TR dimers. This was accompanied by conversion of the single-phase association kinetic curve to a biphasic curve. Similar effects, on conversion of monomers to dimers or $\mathrm{T}_{3}$ association, were not seen with a mutant (TR $\beta$ L 422R) that only forms monomers indicating that both effects require the dimer interface at the junction of $\mathrm{H} 10$ and H11 (Fig. 5B). This data supports the notion that biphasic association kinetics are related to the presence of TR monomers and dimers in solution and that $\mathrm{T}_{3}$ exhibits decreased rates of binding to TR dimers.

\section{$T R$ mutants that influence dimer formation alter}

$T_{3}$ dissociation rates

We previously reported that TR mutations that block (L422R, M423R, and P419R; Cunha Lima et al. 2009) or enhance (TR $\beta$ D 355R; Togashi et al. 2005b) TR dimer formation do not significantly alter affinity of $\mathrm{TR}$ for $\mathrm{T}_{3}$ (Ribeiro et al. 2001). As some of these TR mutants exhibit enhanced rates of $\mathrm{T}_{3}$ association relative to wild-type TRs and TR monomers (Fig. 5), basic thermodynamic principles predict that the mutations should alter $\mathrm{T}_{3}$ dissociation rates. Consistent with this formulation, TR $\beta$ mutants that block dimer formation exhibit higher rates of $\mathrm{T}_{3}$ dissociation than wild-type TRs and the magnitude of these effects paralleled effects of the same mutations on $\mathrm{T}_{3}$ association (Table 1 ). In particular, TR $\beta$ L $422 R$ and TR $\beta M 423 R$ exhibited very high association and dissociation rates relative to wild-type TRs. Moreover, $\mathrm{T}_{3}$ dissociated from the TR mutant that only forms dimers (TR $\beta D 355 R$ ) nearly twice as slowly as from wild-type TRs and up to 50-fold more slowly than the TR $\beta$ mutants that only form monomers.

Table 1 Kinetics of binding of thyroid hormone receptor expressed and purified by different methods, containing or not a point mutation, or in heterodimer with retinoid $X$ receptor $(R X R)$

\begin{tabular}{|c|c|c|c|c|c|}
\hline Receptor & $\boldsymbol{K}_{\mathbf{d}}\left(10^{-10} \mathrm{M}\right)$ & $\begin{array}{l}\text { Association first } \\
\text { half-life }(\mathrm{h})\end{array}$ & $\begin{array}{l}\text { Association second } \\
\text { half-life }(\mathrm{h})\end{array}$ & $\begin{array}{l}\text { Dissociation } \\
\text { half-life }(\mathrm{h})\end{array}$ & Characteristic \\
\hline WT FLTR $\beta$ & $2 \cdot 0 \pm 0 \cdot 34$ & $0 \cdot 10 \pm 0 \cdot 03$ & $4 \cdot 8 \pm 2 \cdot 6$ & $6 \cdot 7 \pm 1 \cdot 0$ & Monomers and dimers \\
\hline His-tag purified LBD & $2 \cdot 3 \pm 0.65$ & $0 \cdot 17 \pm 0.07$ & $6 \cdot 1 \pm 1 \cdot 1$ & $6 \cdot 2 \pm 1 \cdot 2$ & Monomers and dimers \\
\hline Purified LBD & $1 \cdot 6 \pm 0.39$ & $0 \cdot 15 \pm 0 \cdot 12$ & None & $5 \cdot 6 \pm 0 \cdot 46$ & Monomers \\
\hline P419R & $3 \cdot 5 \pm 0 \cdot 41$ & $0 \cdot 14 \pm 0 \cdot 23$ & None & $3 \cdot 1 \pm 0 \cdot 50$ & Monomers \\
\hline L422R & $1 \cdot 8 \pm 0 \cdot 4$ & $0.03 \pm 0.009$ & None & $1 \cdot 5 \pm 0 \cdot 38$ & Monomers \\
\hline M423R & $1 \cdot 7 \pm 0.45$ & $0.02 \pm 0.005$ & None & $0 \cdot 2 \pm 0 \cdot 05$ & Monomers \\
\hline D355R & $1 \cdot 3 \pm 0.29$ & $0.92 \pm 0.14$ & None & $10 \cdot 8 \pm 1 \cdot 20$ & Dimers \\
\hline TR:RXR & $1 \cdot 2 \pm 0.66$ & $0 \cdot 23 \pm 0 \cdot 04$ & None & $1 \cdot 4 \pm 0 \cdot 49$ & Heterodimers \\
\hline
\end{tabular}

$K_{\mathrm{d}}$, dissociation constant; WT FLTR $\beta$, wild-type full-length thyroid hormone receptor beta; His-tag, histidine tagging; LBD, ligand binding domain. 

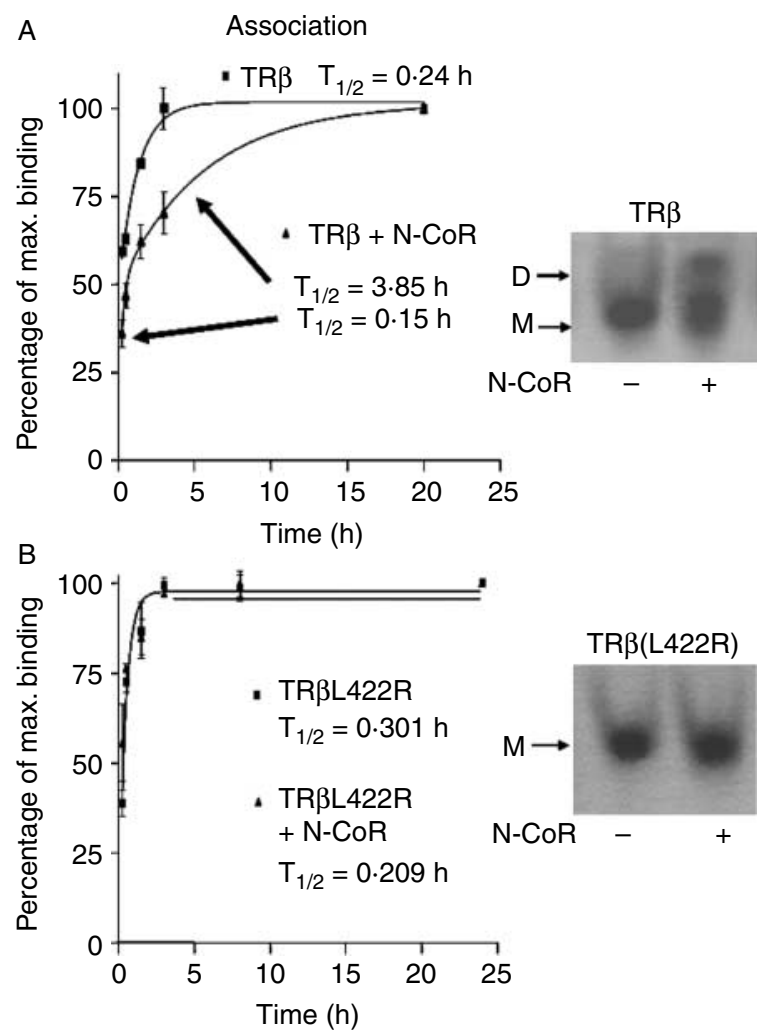

Figure 5 A corepressor (N-CoR) peptide induces TR LBD monomer to dimer conversion in solution and inhibits $T_{3}$ association. (A) The inset shows an image of a Coomassie blue-stained non-denaturing polyacrylamide gel, as in Fig. $3 \mathrm{~A}$, used to compare purified TR $\beta$ LBD monomers and a similar TR $\beta$ LBD monomer preparation after incubation for $30 \mathrm{~min}$ with a corepressor ID peptide. Note that this preparation consists of monomers and dimers. The main panel shows $\mathrm{T}_{3}$ association with purified TR LBD monomers or TR LBD+ $\mathrm{N}-\mathrm{CoR}$ (monomer/dimer mix), as in Fig. 1A. (B) As for Fig. 6A, except that the experiment is performed with a TR $\beta$ LBD L422R mutant that can only form monomers.

\section{$R X R-T R s$ bind and release $T_{3}$ rapidly}

As TRs form heterodimers with RXR, it is relevant to examine binding of $\mathrm{T}_{3}$ to this species. We prepared in vitro translated TRs \pm RXRs and examined association rates of ligand with each preparation. $\mathrm{T}_{3}$ bound to RXR-TRs with rapid single-phase kinetics similar to those observed with TR monomers (Fig. 6A). Gel shift experiments confirmed that RXR-TR mixtures comprised heterodimers, as judged by increased mobility of the complex relative to that of TR homodimers on a TRE oligonucleotide (DR-4; Fig. 6B).

$\mathrm{T}_{3}$ also dissociated rapidly from RXR-TRs, even faster than from wild-type TRs or purified preparations of TR-LBD monomers $\left(\mathrm{T}_{1 / 2}\right.$ for $\mathrm{T}_{3}$ dissociation of $1.4 \mathrm{~h}$ for heterodimer versus $6.7 \mathrm{~h}$ for wild-type TRs and $5.6 \mathrm{~h}$ for the TR $\beta$ LBD monomer (Table 1)). These results emphasize that TR exhibits major differences in ligand association and dissociation kinetics when it is a monomer or homodimer versus a heterodimer.

\section{Discussion}

In this study, we have shown that the oligomeric state of the TR influences $T_{3}$ binding kinetics. Our investigation was prompted by our previous observation that mutations in the TR LBD surface that mediates dimer and heterodimer formation increase association rates without altering affinity of TRs for $T_{3}$ (Cunha Lima et al. 2009). Our analysis of $T_{3}$ association with TRs reveals better fit of the curves with biphasic kinetics rather than single-phase kinetics: $T_{3}$ binds TRs with a rapid first phase (half-life $\pm 0 \cdot 1 \mathrm{~h}$ ) followed by a slower second phase (half-life $\pm 5 \mathrm{~h}$ ). This is a fundamental property of $\mathrm{T}_{3}$ association with TR-LBDs; it is seen with both TR isoforms and TR truncations overlapping the DBD-LBD and LBD prepared in a variety of systems.

In principle, biphasic association kinetics could be explained in several ways, including existence of multiple ligand binding sites on the target protein, but two lines of evidence suggest that our TR preparations comprised two populations with different $T_{3}$ binding properties. First, our
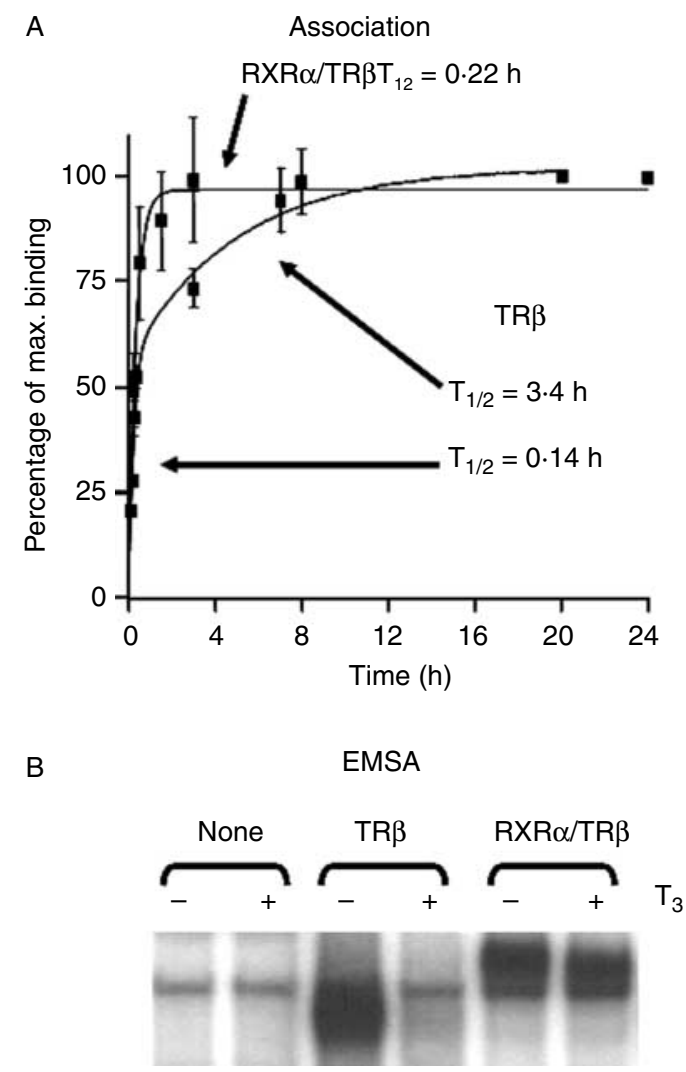

Figure 6 RXR-TR Heterodimers bind and release $T_{3}$ rapidly. (A) Determination of $T_{3}$ association rates with in vitro translated TRs or RXR-TR mix, as in Fig. 1A. Note that RXR-TR heterodimer formation enhances rates of $T_{3}$ binding compared with TR only. (B) Incubation of in vitro translated TR $\beta$ with in vitro translated RXR converts TR homodimers to RXR-TR heterodimers, as judged by reduced mobility of complex formed with a radiolabeled DR-4 element in a gel shift assay. 

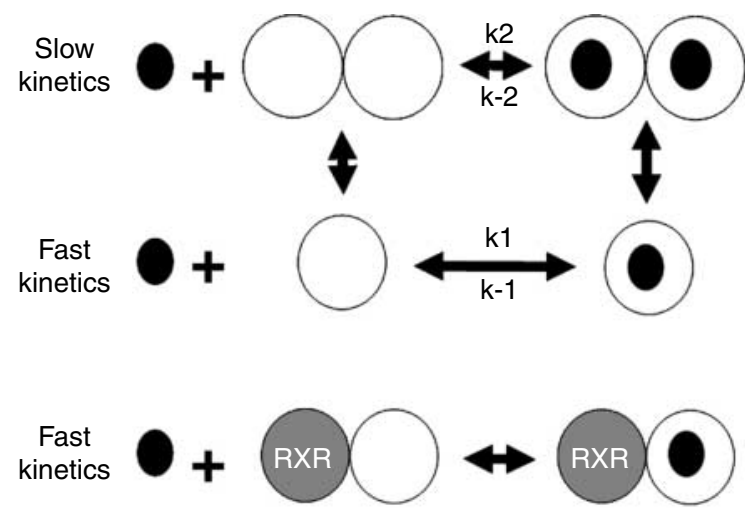

Figure 7 Model for $\mathrm{T}_{3}$ binding to TRs. A schematic representation of $\mathrm{T}_{3}$ binding to TRs. $\mathrm{T}_{3}$ is represented by small black ovals, TRs by large white circles, and RXRs by shaded circles. $T_{3}$ binds rapidly to monomers and slowly to dimers and subsequently converts dimers to monomers. Thus, $T_{3}$ association measurements reflect contributions of $k 1$ and $k 2$, whereas dissociation measurements primarily reflect k-1.

TR X-ray crystal structures indicate that there is only a single high-affinity hormone binding pocket (Wagner et al. 2001, Sandler et al. 2004). Next, previous analyses of $\mathrm{T}_{3}$ equilibrium binding and dissociation kinetics (Suthers et al. 1976, Nguyen et al. 2002, 2005, Cunha Lima et al. 2009), confirmed here, had revealed no evidence for multiple $\mathrm{T}_{3}$ binding sites. Thus, the simplest explanation that reconciles our findings is that unliganded TRs comprised two distinct species that bind $\mathrm{T}_{3}$ at different rates and that $T_{3}$ converts TRs to a single species with uniform ligand binding and dissociation properties.

The data reported in the paper support this formulation and indicate that biphasic association kinetics reflects rapid $T_{3}$ binding to TR monomers and slow $\mathrm{T}_{3}$ binding to dimers (Fig. 7). Analyses of purified unliganded TRs on nondenaturing gels and by analytical ultracentrifugation reveal a mix of TR monomers and dimers (Fig. 2). Furthermore, several lines of evidence indicate that $T_{3}$ rapidly binds to $T R$ monomers and slowly to dimers (Figs $3-5$, Table 1). 1) Short $\mathrm{T}_{3}$ incubations selectively increase TR monomer mobility in non-denaturing gels, indicative of rapid hormone association with this species and not with dimers. 2) $T_{3}$ binds purified TR LBD monomers with rapid single-phase kinetics $\left(\mathrm{T}_{1 / 2}=\right.$ $0 \cdot 03-0 \cdot 27 \mathrm{~h}$; comparable to the first phase of $\mathrm{T}_{3}$ association with TRs, $\mathrm{T}_{1 / 2}=0 \cdot 07-0 \cdot 13 \mathrm{~h}$ ). 3) The TR $\beta \mathrm{D} 355 \mathrm{R}$ mutant (Togashi et al. 2005b) only forms dimers and binds $\mathrm{T}_{3}$ with slow single-phase kinetics $\left(\mathrm{T}_{1 / 2}=0.92 \mathrm{~h}, 6-15\right.$ times slower than TR LBD monomers and up to 46-fold slower than TR $\beta$ mutants that only form monomers). 5) An N-CoR peptide promotes dimer formation within preparations of purified TR LBD monomers and restores biphasic ligand binding kinetics.

Our data are also consistent with another prediction of our model that $\mathrm{T}_{3}$ converts $\mathrm{TRs}$ to a single species with uniform ligand binding properties. Analytical ultracentrifugation (Fig. 2) and sizing chromatography analysis (not shown) reveal that $\mathrm{T}_{3}$ converts $\mathrm{TR}$ dimers to monomers. Furthermore, $T_{3}$ dissociates from wild-type TRs at a comparable rate $\left(\mathrm{T}_{1 / 2}=5-7 \mathrm{~h}\right)$ to purified LBD monomers $\left(\mathrm{T}_{1 / 2}=5 \cdot 6 \mathrm{~h}\right)$, consistent with the prediction that measurements of TR ligand dissociation kinetics reflect $\mathrm{T}_{3}$ release from monomers.

Heterodimer formation also influences $T_{3}$ binding kinetics. We find that RXR-TRs exhibit unique properties that are distinct from TR-TR homodimers or TR monomers. RXR-TRs bind $\mathrm{T}_{3}$ with rapid single-phase kinetics, comparable to monomers (Fig. 7; Table 1), but release $\mathrm{T}_{3}$ more rapidly than $\mathrm{TR}$ monomers $\left(\mathrm{T}_{1 / 2}=1.4 \mathrm{~h}\right.$ for RXR-TRs versus $5 \cdot 6 \mathrm{~h}$ for TR LBD monomers).

Together, our data suggest that interactions at the TR dimer/heterodimer surface influence the overall LBD conformation to regulate $T_{3}$ binding kinetics. Thus, we propose that 1) TR homodimer formation alters LBD conformation to slow the rate of $\mathrm{T}_{3}$ entry to the pocket. 2) $\mathrm{T}_{3}$ remodels the TR-LBD to prevent homodimer formation; although it was previously known that $\mathrm{T}_{3}$ binding inhibits TR homodimer formation on DNA (Togashi et al. 2005b, Jeyakumar et al. 2008), our data represent direct proof that $T_{3}$ impairs dimer formation via effects on LBDs. 3) RXR-TR formation induces a novel TR conformation distinct from homodimers or monomers, with RXR-TRs able to bind $\mathrm{T}_{3}$ more rapidly than TR-TR homodimers and release $T_{3}$ more rapidly than TR monomers. The fact that the $\mathrm{N}-\mathrm{CoR}$ ID peptide, which stabilizes the unliganded TR LBD by binding to the H3-H5 region ( $\mathrm{Hu}$ \& Lazar 1999, Marimuthu et al. 2002), induces that homodimer formation through $\mathrm{H} 10-\mathrm{H} 11$ on the opposite side of the domain represents further evidence that the dimer surface is allosterically coupled to other parts of the LBD and recent H/D exchange data (Figueira et al. 2011) confirms that hormone binding results in conformational alterations that affect the entire domain including the dimer surface.

Analysis of dimerization and kinetics of binding has also been performed with estrogen receptors (ERs) and results link dimerization to stabilization of the ligand and decreasing in kinetics (Tamrazi et al. 2002). Another study with ER demonstrated that WT protein and mutants Y537S and Y537E exhibited biphasic dissociation kinetics, which, according to the author, was also due to the presence of dimers and monomers (Zhong \& Skafar 2002).

What structural elements couple the dimer surface to changes in $\mathrm{T}_{3}$ binding kinetics? We previously proposed that homodimer and heterodimer surfaces are partially overlapping and that $\mathrm{T}_{3}$ blocks dimer formation but not RXR-TR heterodimer formation, by remodeling homodimer-specific portions of the LBD surface, including the charge cluster that is target for the D355R mutation used here (Togashi et al. 2005a). Thus, one possibility is that TR homodimer and heterodimer formation influences $\mathrm{T}_{3}$ binding kinetics by altering the conformation of these homodimer- and heterodimer-specific regions of the dimer interface. Another possibility is that TR dimer and heterodimer partners could alter the conformation of the region that comprises the 
common homodimer/heterodimer interface at the $\mathrm{H} 10 / \mathrm{H} 11$ junction to alter TR LBD hormone binding properties. A piece of evidence that the $\mathrm{H} 10-\mathrm{H} 11$ region could influence ligand binding kinetics is that mutations in this region that inhibit dimer and heterodimer formation (TR $\beta$ P419R; TR $\beta L 422 R$, and TR $\beta M 423 R$ ) exhibit differences in the magnitude of their effects on $\mathrm{T}_{3}$ association and dissociation rates (Cunha Lima et al. 2009). Furthermore, HD exchange experiments (Figueira et al. 2011) confirm that hormone binding results in remodeling of the dimer surface.

We emphasize that enhanced dimer formation by the TR $\beta$ D355R mutant involves novel surfaces in the H10-H11 loop and H8-H6 that lie close to the classic dimer surface at H10-H11 but are not identical to this interaction surface (Jouravel et al. 2009). The fact that dimer formation through an unusual surface affects hormone binding kinetics in a similar manner to native dimer formation raises the possibility that effects of dimerization on ligand binding kinetics may be related partly to physical occlusion of ligand entry/exit routes as well as allosteric connections between the LBP and the classic dimer face. Indeed, the TR $\beta$ D 355R dimer blocks one of the predicted ligand exit routes identified by molecular dynamics at H8 (Martinez et al. 2005). Interestingly, this is similar to predictions made from molecular dynamics simulations with ER monomers and dimers (Sonoda et al. 2008), which suggests that dimer interactions at $\mathrm{H} 8$ specifically occlude a major estrogen exit route.

Overall, the fact that TR oligomer formation influences ligand binding kinetics lends support to the concept that TR and NR LBDs influence the conformation and activities of their dimer and heterodimer partners and raise the possibility that these effects could be important in living cells (Schueler et al. 1990, Ribeiro et al. 2001). For example, TR does not usually allow activation of RXR heterodimer partner by its cognate ligand (9-cis retinoic acid), whereas other NRs, such as the liver $\mathrm{X}$ receptor, do permit $\mathrm{RXR}$ activation in vivo (Shulman et al. 2004). Thus, effects of TR oligomer formation on ligand binding kinetics could be important for TR action in living cells. As RXR-TRs bind and release $T_{3}$ faster than wild-type TRs, we expect that this species should respond more rapidly to alterations in intracellular $T_{3}$ than other TR species. Furthermore, the fact that TR dimers are resistant to $T_{3}$ binding is consistent with previous proposals that this species is important for gene regulation in the absence of $\mathrm{T}_{3}$ (Williams et al. 1992). Improved understanding of influences of homodimer and heterodimer formation on ligand binding, and vice versa, could improve our ability to develop drugs to selectively bind and modulate activities of particular TR oligomers.

\section{Declaration of interest}

The authors declare that there is no conflict of interest that could be perceived as prejudicing the impartiality of the research reported.

\section{Funding}

This work was supported by National Institute of Health (grants DK41482 and DK51281).

\section{Acknowledgements}

We thank Prof. John D Baxter and Dr Paul Webb for giving us the opportunity to develop this work at the Diabetes Center of University of California San Francisco.

\section{References}

Baxter JD \& Webb P 2009 Thyroid hormone mimetics: potential applications in atherosclerosis, obesity and type 2 diabetes. Nature Reviews. Drug Discovery 8 308-320. (doi:10.1038/nrd2830)

Bleicher L, Aparicio R, Nunes FM, Martinez L, Gomes Dias SM, Figueira AC, Santos MA, Venturelli WH, da Silva R, Donate PM et al. 2008 Structural basis of GC-1 selectivity for thyroid hormone receptor isoformas. BMC Structural Biology 8 1-13. (doi:10.1186/1472-6807-8-8)

Carlson KE, Choi I, Gee A, Katzenellenbogen BS \& Katzenellenbogen JA 1997 Altered ligand binding properties and enhanced stability of a constitutively active estrogen receptor: evidence that an open pocket conformation is required for ligand interaction. Biochemistry 36 14897-14905. (doi:10.1021/bi971746l)

Cunha Lima ST, Nguyen NH, Togashi M, Apriletti J, Nguyen P, Polikarpov I, Scanlan TS, Baxter JD \& Webb P 2009 Differential effects of TR ligands on hormone dissociation rates: evidence for multiple ligand entry/exit pathways. Journal of Steroid Biochemistry and Molecular Biology 117 125-131. (doi:10.1016/j.jsbmb.2009.08.003)

Darimont BD, Wagner RL, Apriletti JW, Stallcup MR, Kushner PJ, Baxter JD, Fletterick RJ \& Yamamoto KR 1998 Structure and specificity of nuclear receptor-coactivator interactions. Genes and Development 12 3343-3356. (doi:10.1101/gad.12.21.3343)

Feng W, Ribeiro RC, Wagner RL, Nguyen H, Apriletti JW, Fletterick RJ, Baxter JD, Kushner PJ \& West BL 1998 Hormone-dependent coactivator binding to a hydrophobic cleft on nuclear receptors. Science 280 1747-1749. (doi:10.1126/science.280.5370.1747)

Figueira AC, Neto Mde O, Bernardes A, Dias SM, Craievich AF, Baxter JD, Webb P \& Polikarpov I 2007 Low-resolution structures of thyroid hormone receptor dimers and tetramers in solution. Biochemistry 46 1273-1283. (doi:10.1021/bi061698h)

Figueira AC, Saidemberg DM, Souza PC, Martínez L, Scanlan TS, Baxter JD, Skaf MS, Palma MS, Webb P \& Polikarpov I 2011 Analysis of agonist and antagonist effects on thyroid hormone receptor conformation by hydrogen/deuterium exchange. Molecular Endocrinology 25 15-31. (doi:10. 1210/me.2010-0202)

Glass CK \& Rosenfeld MG 2000 The coregulator exchange in transcriptional functions of nuclear receptors. Genes and Development 14 121-141. (doi:10. $1101 /$ gad.14.2.121)

Hu X \& Lazar MA 1999 The CoRNR motif controls the recruitment of corepressors by nuclear hormone receptors. Nature 402 93-96. (doi:10. 1038/47069)

Huber BR, Desclozeaux M, West BL, Cunha Lima ST, Nguyen HT, Baxter JD, Ingraham HA \& Fletterick RJ 2003a Thyroid hormone receptor-beta mutations conferring hormone resistance and reduced corepressor release exhibit decreased stability in the N-terminal ligand-binding domain. Molecular Endocrinology 17 107-116. (doi:10.1210/me.2002-0097)

Huber BR, Sandler B, West BL, Cunha Lima ST, Nguyen HT, Apriletti JW, Baxter JD \& Fletterick RJ $2003 b$ Two resistance to thyroid hormone mutants with impaired hormone binding. Molecular Endocrinology 17 643-652. (doi:10.1210/me.2002-0095)

Jeyakumar M, Webb P, Baxter JD, Scanlan TS \& Katzenellenbogen JA 2008 Quantification of ligand-regulated nuclear receptor corepressor and 
coactivator binding, key interactions determining ligand potency and efficacy for the thyroid hormone receptor. Biochemistry 47 7465-7476. (doi:10.1021/bi800393u)

Jouravel N, Sablin E, Togashi M, Baxter JD, Webb P \& Fletterick RJ 2009 Molecular basis for dimer formation of TR beta variant D355R. Proteins $\mathbf{7 5}$ 111-117. (doi:10.1002/prot.22225)

Laudet V \& Gronemeyer H 2002. The Nuclear Receptor Facts Book. Factsbook Series. edn 1, pp 462. London: Academic Press.

Marimuthu A, Feng W, Tagami T, Nguyen H, Jameson JL, Fletterick RJ, Baxter JD \& West BL 2002 TR surfaces and conformations required to bind nuclear receptor corepressor. Molecular Endocrinology 16 271-286. (doi:10. 1210/me.16.2.271)

Martinez L, Sonoda MT, Webb P, Baxter JD, Skaf MS \& Polikarpov I 2005 Molecular dynamics simulations reveal multiple pathways of ligand dissociation from thyroid hormone receptors. Biophysical Journal 89 2011-2023. (doi:10.1529/biophysj.105.063818)

Martinez L, Webb P, Polikarpov I \& Skaf MS 2006 Molecular dynamics simulations of ligand dissociation from thyroid hormone receptors: evidence of the likeliest escape pathway and its implications for the design of novel ligands. Journal of Medicinal Chemistry 49 23-26. (doi:10.1021/jm050805n)

Moore TW, Mayne CG \& Katzenellenbogen JA 2010 Minireview: not picking pockets: nuclear receptor alternate-site modulators (NRAMs). Molecular Endocrinology 24 683-695. (doi:10.1210/me.2009-0362)

Motulsky H \& Christopoulos A 2003 Fitting models to biological data using linear and nonlinear regression. A practical guide to curve fitting. edn 4 , pp 351. Oxford University Press.

Nettles KW \& Greene GL 2005 Ligand control of coregulator recruitment to nuclear receptors. Annual Review of Physiology 67 309-333. (doi:10.1146/ annurev.physiol.66.032802.154710)

Nguyen NH, Apriletti JW, Cunha Lima ST, Webb P, Baxter JD \& Scanlan TS 2002 Rational design and synthesis of a novel thyroid hormone antagonist that blocks coactivator recruitment. Journal of Medicinal Chemistry $\mathbf{4 5}$ 3310-3320. (doi:10.1021/jm0201013)

Nguyen NH, Apriletti JW, Baxter JD \& Scanlan TS 2005 Hammett analysis of selective thyroid hormone receptor modulators reveals structural and electronic requirements for hormone antagonists. Journal of the American Chemical Society 127 4599-4608. (doi:10.1021/ja0440093)

Pissios P, Tzameli I, Kushner P \& Moore DD 2000 Dynamic stabilization of nuclear receptor ligand binding domains by hormone or corepressor binding. Molecular Cell 6 245-253. (doi:10.1016/S1097-2765(00)00026-5)

Ribeiro RC, Feng W, Wagner RL, Costa CH, Pereira AC, Apriletti JW, Fletterick RJ \& Baxter JD 2001 Definition of the surface in the thyroid hormone receptor ligand binding domain for association as homodimers and heterodimers with retinoid X receptor. Journal of Biological Chemistry 276 14987-14995. (doi:10.1074/jbc.M010195200)

Sandler B, Webb P, Apriletti JW, Huber BR, Togashi M, Cunha Lima ST, Juric S, Nilsson S, Wagner R, Fletterick RJ et al. 2004 Thyroxine-thyroid hormone receptor interactions. Journal of Biological Chemistry 279 55801-55808. (doi:10.1074/jbc.M410124200)

Schueler PA, Schwartz HL, Strait KA, Mariash CN \& Oppenheimer JH 1990 Binding of 3,5, $3^{\prime}$-triiodothyronine $\left(\mathrm{T}_{3}\right)$ and its analogs to the in vitro translational products of c-erbA protooncogenes: differences in the affinity of the alpha- and beta-forms for the acetic acid analog and failure of the human testis and kidney alpha- 2 products to bind $\mathrm{T}_{3}$. Molecular Endocrinology 4 227-234. (doi:10.1210/mend-4-2-227)

Shulman AI, Larson C, Mangelsdorf DJ \& Ranganathan R 2004 Structural determinants of allosteric ligand activation in RXR heterodimers. Cell 116 417-429. (doi:10.1016/S0092-8674(04)00119-9)
Sonoda MT, Martinez L, Webb P, Skaf MS \& Polikarpov I 2008 Ligand dissociation from estrogen receptor is mediated by receptor dimerization: evidence from molecular dynamics simulations. Molecular Endocrinology 22 1565-1578. (doi:10.1210/me.2007-0501)

Suthers MB, Pressley LA \& Funder JW 1976 Glucocorticoid receptors: evidence for a second, non-glucocorticoid binding site. Endocrinology $\mathbf{9 9}$ 260-269. (doi:10.1210/endo-99-1-260)

Tamrazi A, Carlson KE, Daniels JR, Hurth KM \& Katzenellenbogen JA 2002 Estrogen receptor dimerization: ligand binding regulates dimer affinity and dimer dissociation rate. Molecular Endocrinology 16 2706-2719. (doi:10. 1210/me.2002-0250)

Togashi M, Borngraeber S, Sandler B, Fletterick RJ, Webb P \& Baxter JD $2005 a$ Conformational adaptation of nuclear receptor ligand binding domains to agonists: potential for novel approaches to ligand design. Journal of Steroid Biochemistry and Molecular Biology 93 123-137. (doi:10. 1016/j.jsbmb.2005.01.004)

Togashi M, Nguyen P, Fletterick R, Baxter JD \& Webb P 2005 b Rearrangements in thyroid hormone receptor charge clusters that stabilize bound 3,5',5-triiodo-L-thyronine and inhibit homodimer formation. Journal of Biological Chemistry 280 25665-25673. (doi:10.1074/jbc. M501615200)

Velasco LF, Togashi M, Walfish PG, Pessanha RP, Moura FN, Barra GB, Nguyen P, Rebong R, Yuan C, Simeoni LA et al. 2007 Thyroid hormone response element organization dictates the composition of active receptor. Journal of Biological Chemistry 282 12458-12466. (doi:10.1074/jbc.M610700200)

Wagner RL, Huber BR, Shiau AK, Kelly A, Cunha Lima ST, Scanlan TS, Apriletti JW, Baxter JD, West BL \& Fletterick RJ 2001 Hormone selectivity in thyroid hormone receptors. Molecular Endocrinology 15 398-410. (doi:10. 1210/me.15.3.398)

Webb P, Anderson CM, Valentine C, Nguyen P, Marimuthu A, West BL, Baxter JD \& Kushner PJ 2000 The nuclear receptor corepressor (N-CoR) contains three isoleucine motifs (I/LXXII) that serve as receptor interaction domains (IDs). Molecular Endocrinology 14 1976-1985. (doi:10.1210/me.14. 12.1976)

Webb P, Nguyen NH, Chiellini G, Yoshihara HA, Cunha Lima ST, Aprilett JW, Ribeiro RC, Marimuthu A, West BL, Goede P et al. 2002 Design of thyroid hormone receptor antagonists from first principles. Journal of Steroid Biochemistry and Molecular Biology 83 59-73. (doi:10.1016/S0960-0760(02) 00270-4)

Williams GR, Harney JW, Moore DD, Larsen PR \& Brent GA 1992 Differential capacity of wild type promoter elements for binding and trans-activation by retinoic acid and thyroid hormone receptors. Molecular Endocrinology 6 1527-1537. (doi:10.1210/me.6.10.1527)

Yen PM 2001 Physiological and molecular basis of thyroid hormone action. Physiological Reviews 81 1097-1142.

Zhong L \& Skafar DF 2002 Mutations of tyrosine 537 in the human estrogen receptor-alpha selectively alter the receptor's affinity for estradiol and the kinetics of the interaction. Biochemistry 41 4209-4217. (doi:10.1021/ bi0121095)

\section{Received in final form 26 March 2011 \\ Accepted 20 April 2011 Made available online as an Accepted Preprint 20 April 2011}

